\title{
Relation between admission time, haemodynamic measurements, and prognosis in acute myocardial infarction ${ }^{\star}$
}

\author{
JÜRGEN MEYER, RAIMUND ERBEL, HANS-JÜRGEN RUPPRECHT, \\ RAINER VON ESSEN, WOLFGANG MERX, SVEN EFFERT
}

From the Department of Internal Medicine I, Rheinisch-Westfälische Technische Hochschule, Aachen, West Germany

SUMmaRy Pulmonary arterial end-diastolic pressure, cardiac index, and stroke work index were measured via a thermistor-tipped balloon catheter and monitored for $51 \pm 51$ hours in 226 patients admitted with an acute myocardial infarction (184 survivors and 42 non-survivors). Mortality was related to time of admission after onset of symptoms of infarction. Of 69 patients in group A 13 died in hospital (18.8\%) one to four hours after onset; in group B (five to eight hours after onset) eight of 71 patients $(11 \%)$ died five to eight hours after onset; four of 26 patients in group $\mathrm{C}(15 \%)$ died nine to 12 hours after onset; 15 of 42 patients (36\%) in group D died 13 to 24 hours after onset; and two of 18 patients in group $\mathrm{E}$ died (11\%) more than 24 hours after onset. Irrespective of admission time, haemodynamic findings in survivors were significantly better than in non-survivors. During the first eight to 12 hours after onset of infarction cardiac index and stroke work index were normal or above normal, with raised left ventricular filling pressures. In patients admitted later, this compensatory mechanism had often collapsed. Where pump failure with subnormal cardiac index and stroke work index were present mortality was increased. All four patients dying from acute myocardial rupture had significantly higher values of cardiac index and stroke work index and lower values of pulmonary artery end-diastolic pressure compared with those dying from other causes.

Although the initial haemodynamic values give some prognostic information, longitudinal analysis provides insight into the evolving myocardial disturbance and compensatory mechanisms. If the initial values of pulmonary artery end-diastolic pressure and cardiac and stroke work indices remain normal or become stable after a transient disturbance in the acute phase, prognosis is good. If, however, these values deteriorate or remain abnormal, prognosis is poor. Typically such patients have suffered large infarctions with a tendency to expansion. If the haemodynamic situation during the first 24 hours after onset of infarction remains stable for 12 to 15 hours, haemodynamic monitoring may be stopped; the chance of relapse in such patients was found to be below $10 \%$. Late deteriorazion, usually manifest by further pain or by electrocardiographic or enzyme changes, should be an indication to restart haemodynamic monitoring so that treatment can be chosen and adjusted optimally. These haemodynamic measurements in patients treated traditionally with vasodilators, positive inotropic agents, and fluid will form the basis for comparison of measurements in patients who are now treated within the first eight hours with selective intracoronary thrombolysis and, if possible, with adjacent intracoronary balloon dilatation of the underlying coronary artery stenosis.

The introduction of the double-lumen Swan-Ganz catheter ${ }^{1}$ has increased our knowledge of the haemo-

* Supported by the Deutsche Forschungsgemeinschaft Bonn-Bad Godesberg Sonderforschungsbereich 109.

Received for publication 27 April 1981 dynamic changes in acute myocardial infarction ${ }^{2-7}$ and the necessary treatment resulting from them. The initial measurements of pulmonary arterial enddiastolic pressure and cardiac output, and derivation of cardiac stroke work index are already of clinical and prognostic importance. ${ }^{8-12}$ Haemodynamic findings 
in the early phase of myocardial infarction, however, are subject to continuous change because of alterations in myocardial wall stiffness, influence of circulating endogeneous catecholamines, possible extension and or expansion of the infarction, and local compensatory changes by the healthy parts of the myocardium. ${ }^{12-14}$ These regulatory and adaptive changes within the first 24 hours have not always been taken into consideration. The timing of the measurements in relation to the onset of infarction and comparison with the preceding and succeeding findings are of considerable importance with respect to the clinical assessment and prognosis.

In this study the relation between the time and individual values of haemodynamic measurements, as well as their apparent prognostic significance, have been analysed in 226 patients who came to the coronary care unit in the early phase of an acute myocardial infarction.

\section{Subjects and methods}

Two hundred and twenty-six patients (172 men, 54 women) with an acute myocardial infarction were studied haemodynamically immediately after admission to hospital. After detailed explanation about the nature of the haemodynamic measurements, the advantages with respect to better clinical management, and mention of the possible complications, all patients gave their consent. Transmural inferior wall infarction occurred in 120 patients (in-hospital mortality $12 \%$ ) and transmural anterior wall infarction in 98 patients (in-hospital mortality 28\%); eight patients had a non-transmural infarction (inhospital mortality $13 \%$ ). A total of 42 patients (18.6\%) died during the hospital phase. The mean age of the survivors was $58.8 \pm 10.6$ years and that of the non-survivors $67 \cdot 6 \pm 9 \cdot 9$ years (standard deviation).

The time of onset of the infarction was determined as precisely as possible. Patients were subdivided into groups according to the time between the presumed moment of onset of infarction and the first haemodynamic measurements. In 69 patients $(30.5 \%)$ the interval was one to four hours (time group A), in 71 patients $(31 \%)$ five to eight hours (time group B), in 26 patients (11\%) nine to 12 hours (time group C), in 42 patients $(18.6 \%) 13$ to 24 hours (time group D), and in 18 patients $(8 \%)$ more than 24 hours (time group E). As a rule, within the first hour after admission a double-lumen Swan-Ganz catheter was passed transcutaneously via an anticubital vein into the pulmonary artery, with the aid of fluoroscopy.

Initially the pressures in the right atrium, right ventricle, pulmonary artery, and pulmonary wedge position were recorded. Pulmonary arterial pressure was then monitored continuously. The systemic arterial pressure was taken by cuff, except in shocked patients where it was obtained via a Teflon cannula in the brachial or femoral artery. The cardiac output and stroke volume were determined by the thermodilution method using a bedside cardiac output computer. ${ }^{\star}$ The cardiac index $(\mathrm{CI})$ and stroke volume index (SVI) were then determined and stroke work index (SWI) calculated by the formula:

SWI $\left[\mathrm{g} \mathrm{m} / \mathrm{m}^{2}\right]=$ [SVI 0.66 (mean systolic arterial pressure) - PAEDP] $\times 0.0136$.

Table 1 Limiting values for separating patients into different haemodynamic groups

\begin{tabular}{llll}
\hline Group & Clinical picture & $\begin{array}{l}\text { CI } \\
\left(\text { l } / \text { min per } \mathrm{m}^{2}\right)\end{array}$ & $\begin{array}{l}\text { PAEDP } \\
(\mathrm{mmHg})\end{array}$ \\
\hline I & $\begin{array}{lll}\text { (a) Normal haemodynamics } \\
\text { (b) Hyperkinesis }\end{array}$ & $>2 \cdot 2-3 \cdot 5$ & $<18$ \\
II & $\begin{array}{l}\text { Isolated pulmonary } \\
\text { congestion }\end{array}$ & $>2 \cdot 5$ & $<18$ \\
III & $\begin{array}{l}\text { Isolated hypoperfusion } \\
\text { Pulmonary congestion }+\end{array}$ & $\leqslant 2 \cdot 2$ & $\geqslant 18$ \\
IV & $\leqslant 2 \cdot 2$ & $<18$ \\
& $\quad$ hypoperfusion & & \\
\hline
\end{tabular}

The patients were divided into four haemodynamic groups according to the values of the pulmonary artery end-diastolic pressure and cardiac index (Table 1). A separate analysis was also undertaken by dividing the patients into four groups according to stroke work index values (above $60 \mathrm{~g} \mathrm{~m} / \mathrm{m}^{2}, 41$ to $60 \mathrm{~g} \mathrm{~m} / \mathrm{m}^{2}, 21$ to $40 \mathrm{~g} \mathrm{~m} / \mathrm{m}^{2}$ and $20 \mathrm{~g} \mathrm{~m} / \mathrm{m}^{2}$ or less). The mean duration of measurements was $51 \pm 51$ hours (standard deviation). All causes of death during the hospital phase were recorded.

\section{Results}

Initially we found normal haemodynamic values in 85 patients (group Ia), irrespective of the admission time (Fig. 1, Table 2). Their prognosis was good (mortality rate $9 \cdot 4 \%$ ). In a further 30 patients $(13 \cdot 3 \%$ ) there was a hyperdynamic situation with a cardiac index of more than $3.5 \mathrm{l} / \mathrm{min}$ per $\mathrm{m}^{2}$ (group $\mathrm{Ib}$ ) and none died. Prognosis with a mortality rate of about $20 \%$ was

Table 2 Initial haemodynamic findings in 226 patients with acute myocardial infarction

\begin{tabular}{lllllll}
\hline $\begin{array}{l}\text { Haemo- } \\
\text { dynamic } \\
\text { group }\end{array}$ & $\begin{array}{l}\text { No. of } \\
\text { patients }\end{array}$ & $\%$ & $\begin{array}{l}\text { Mortality } \\
\text { No. }\end{array}$ & $\begin{array}{l}\text { CI }(I / \mathrm{min} \\
\left.\text { per } \mathrm{m}^{2}\right)\end{array}$ & $\begin{array}{l}\text { PAEDP } \\
(\mathrm{mmHg})\end{array}$ \\
\hline Ia & 85 & 37.6 & 8 & 9.4 & $2 \cdot 8 \pm 0.4$ & $12 \cdot 3 \pm 2 \cdot 8$ \\
Ib & 30 & 13.3 & 0 & 0 & $4 \cdot 2 \pm 0.5$ & $12 \cdot 6 \pm 2 \cdot 8$ \\
II & 67 & 29.6 & 15 & 22.43 & $1 \pm 0.7$ & $23 \cdot 1 \pm 5 \cdot 3$ \\
III & 24 & 10.6 & 5 & 20.8 & $1.9 \pm 0.3$ & $12 \cdot 3 \pm 3.5$ \\
IV & 20 & 8.9 & 14 & 70.0 & $1 \cdot 8 \pm 0.4$ & $24.8 \pm 6.3$ \\
\hline
\end{tabular}

Note: Cardiac index (CI) and pulmonary arterial end-diastolic pressure (PAEDP) results are group means \pm standard deviation.

* Edwards Laboratories, Santa Ana, USA. 


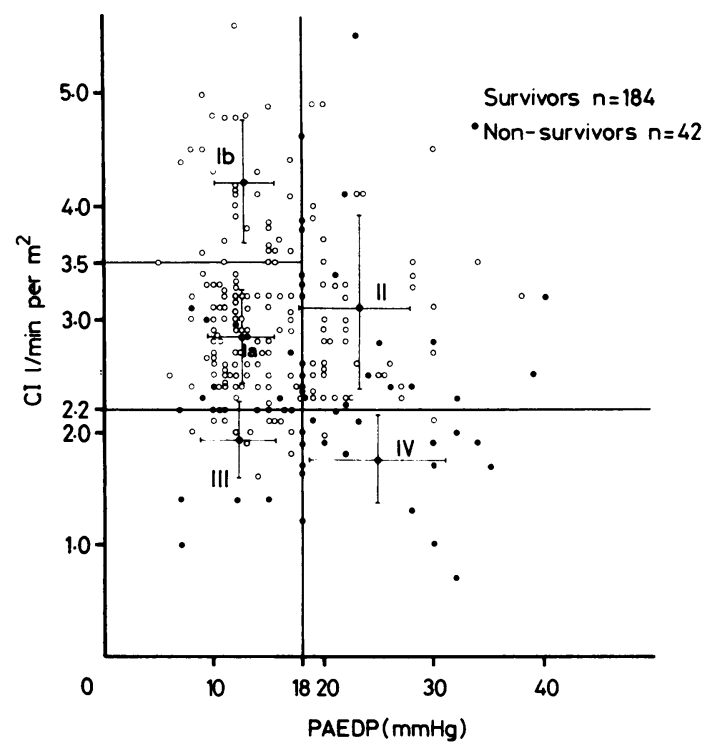

nearly equal in cases of isolated pulmonary congestion (group II) and isolated low output (group III). If both pulmonary congestion and low output were present (group IV), the prognosis was drastically worsened (mortality rate $70 \%$ ). The mean cardiac index of the survivors was $3.0 \pm 0.77 \mathrm{l} / \mathrm{min}$ per $\mathrm{m}^{2}(\mathrm{SD})$ and that of the non-survivors $2 \cdot 3 \pm 0.89 \mathrm{l} / \mathrm{min}$ per $\mathrm{m}^{2}$; their pulmonary end-diastolic pressure was $16 \cdot 0 \pm 6.3 \mathrm{mmHg}$ and $21 \cdot 5 \pm 8.7 \mathrm{mmHg}$, respectively.

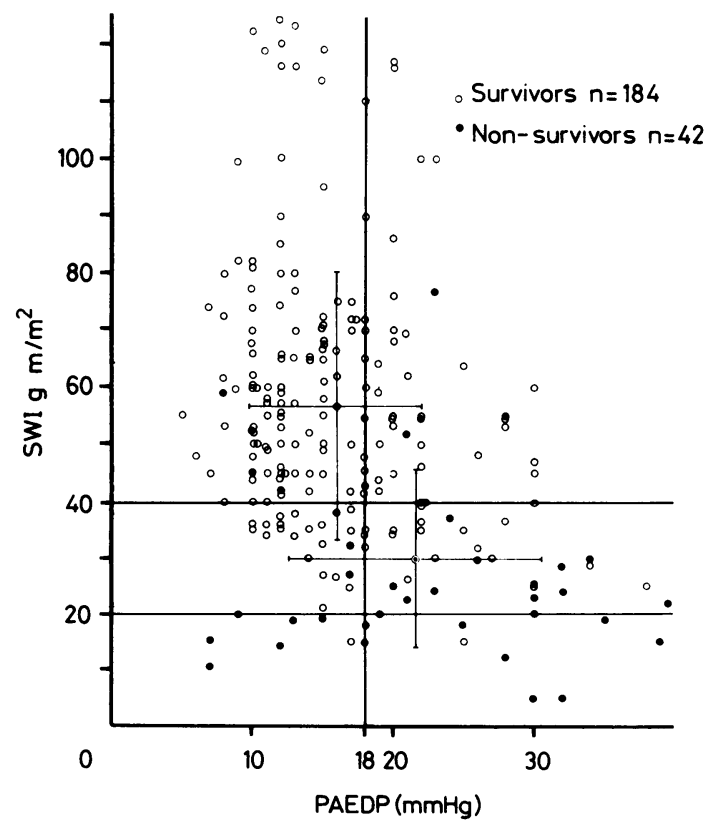

Fig. 1 Initial haemodynamic findings in 226 patients with acute myocardial infarction. Cardiac index $(C I)$ is plotted against pulmonary arterial end-diastolic pressure (PAEDP). Group $I a=$ normal haemodynamics, group $I b=$ hyperkinesis, group $I I=$ isolated pulmonary congestion, group $I I I=$ isolated hypoperfusion, group $I V=$ pulmonary congestion + hypoperfusion. (See Table 2.)

The isolated analysis of stroke work index (Fig. 2, Table 3) also provided important prognostic information, which became even more precise by also considering pulmonary artery end-diastolic pressure. While patients with a stroke work index of more than $60 \mathrm{~g} \mathrm{~m} / \mathrm{m}^{2}$ had a very good prognosis (with pulmonary artery end-diastolic pressure values below $18 \mathrm{mmHg}$ nobody died), patients with stroke work index values below $20 \mathrm{~g} \mathrm{~m} / \mathrm{m}^{2}$, irrespective of

Fig. 2 Distribution of survivors and non-survivors among 226 patients with acute myocardial infarction according to the initial values of stroke work index (SWI) and pulmonary arterial end-diastolic pressure (PAEDP). (See Table 3.) 
Table 3 Relation between initial values of stroke work index (SWI) and pulmonary arterial end-diastolic pressure (PAEDP) and mortality in 226 patients with acute myocardial infarction

\begin{tabular}{|c|c|c|c|c|c|c|c|c|c|c|c|c|c|c|c|}
\hline \multirow{3}{*}{$\begin{array}{l}\text { Value } \\
\text { of } S W I \\
\left(\mathrm{~g} \mathrm{~m} / \mathrm{m}^{2}\right)\end{array}$} & \multicolumn{5}{|c|}{ Total number of patients } & \multicolumn{5}{|c|}{ Patients with PAEDP $<18 \mathrm{mmHg}$} & \multicolumn{5}{|c|}{ Patients with PAEDP $\geqslant m m H g$} \\
\hline & \multirow[t]{2}{*}{ No. } & \multicolumn{2}{|c|}{ Survivors } & \multicolumn{2}{|c|}{ Non-survivors } & \multirow[t]{2}{*}{ No. } & \multicolumn{2}{|c|}{ Survivors } & \multicolumn{2}{|c|}{ Non-survivors } & \multirow[t]{2}{*}{ No. } & \multicolumn{2}{|c|}{ Survivors } & \multicolumn{2}{|c|}{ Non-survivors } \\
\hline & & No. & $\%$ & No. & $\%$ & & No. & $\%$ & No. & $\%$ & & No. & $\%$ & No. & $\%$ \\
\hline$>60$ & 73 & 72 & $98 \cdot 6$ & 1 & $1 \cdot 4$ & 53 & 53 & 100 & - & - & 20 & 19 & 95 & 1 & $5 \cdot 0$ \\
\hline $41-60$ & 77 & 68 & $88 \cdot 3$ & 9 & $11 \cdot 7$ & 51 & 47 & $92 \cdot 2$ & 4 & $7 \cdot 8$ & 26 & 21 & 80.8 & 5 & $19 \cdot 2$ \\
\hline $21-40$ & 58 & 42 & $72 \cdot 4$ & 16 & $27 \cdot 6$ & 27 & 24 & 88.9 & 3 & $11 \cdot 1$ & 31 & 18 & $58 \cdot 1$ & 13 & $41 \cdot 9$ \\
\hline$\leqslant 20$ & 18 & 2 & $11 \cdot 1$ & 16 & $88 \cdot 9$ & 7 & 1 & $14 \cdot 3$ & 6 & $85 \cdot 7$ & 11 & 1 & $9 \cdot 1$ & 10 & $90 \cdot 9$ \\
\hline Total & 226 & 184 & $81 \cdot 4$ & 42 & $18 \cdot 6$ & 138 & 125 & $90 \cdot 6$ & 13 & $9 \cdot 4$ & 88 & 59 & 67.0 & 29 & $33 \cdot 0$ \\
\hline
\end{tabular}

pulmonary artery end-diastolic pressure, had a poor prognosis (mortality rate $90 \%$ ). Between 20 and $40 \mathrm{~g} \mathrm{~m} / \mathrm{m}^{2}$ there was a certain grey zone with mortality rates between $11 \cdot 1$ and $41 \cdot 9 \%$. But, again, with pulmonary artery end-diastolic pressure values below $18 \mathrm{mmHg}$, the prognosis was better. The mean value of stroke work index in survivors was $57 \cdot 4 \pm 23 \cdot 7 \mathrm{~g} \mathrm{~m} / \mathrm{m}^{2}$ and in non-survivors $30 \cdot 2 \pm 16 \cdot 4 \mathrm{~g} \mathrm{~m} / \mathrm{m}^{2}$.

Of the 42 non-survivors, 41 died from cardiac causes and one from apoplexy (Fig. 3, Table 4). Cardiogenic shock occurred in 24 patients,
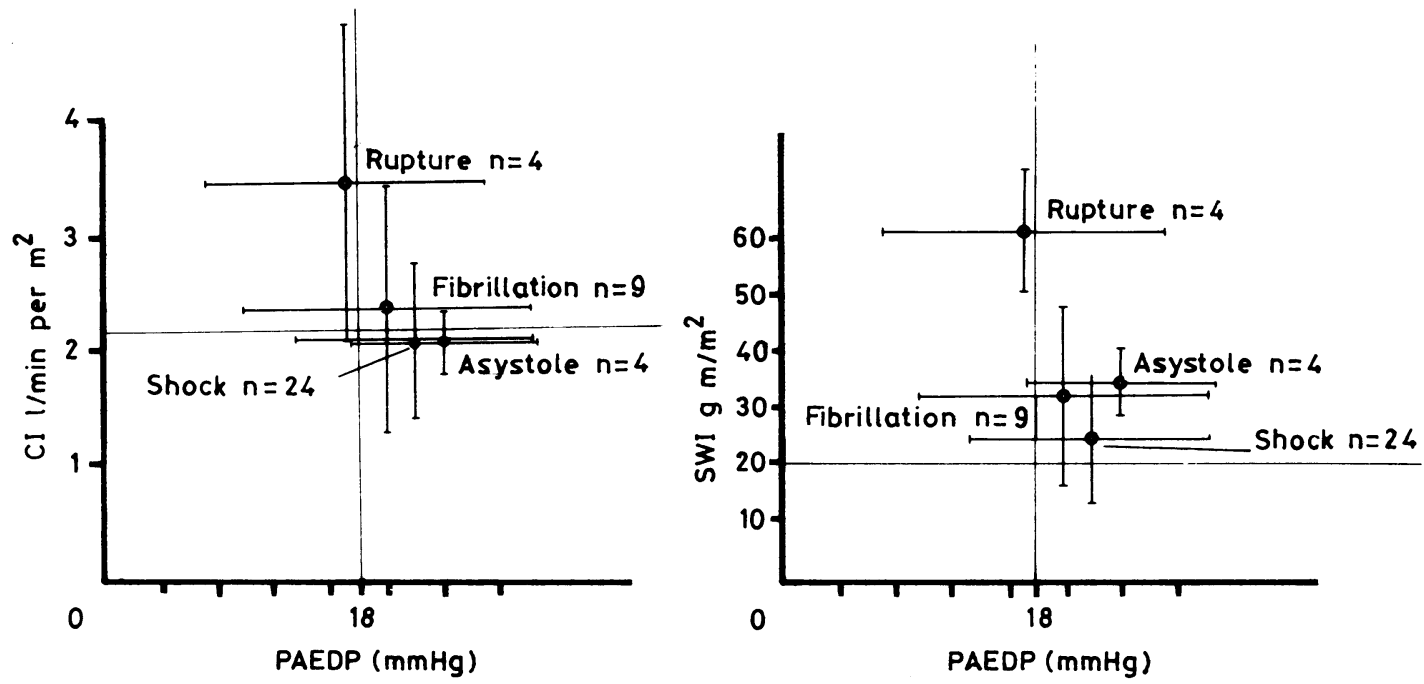

Fig. 3 Initial findings of cardiac index (CI) (on left) and stroke work index (SWI) (on right) vs. pulmonary arterial end-diastolic pressure $(P A E D P)$ in 41 non-survivors in relation to cause of death. (See Table 4.)

Table 4 Initial haemodynamic findings in non-surviving patients: separation according to cause of death

\begin{tabular}{|c|c|c|c|c|c|c|}
\hline $\begin{array}{l}\text { Haemodynamic } \\
\text { variable }\end{array}$ & $\begin{array}{l}\text { (1) Cardiac } \\
\text { rupture } \\
(\text { No. }=4)\end{array}$ & $\begin{array}{l}\text { (2) Ventricular } \\
\text { fibrillation } \\
(\text { No. }=9)\end{array}$ & $\begin{array}{l}\text { (3) Terminal } \\
\text { asystole } \\
(\text { No. }=4)\end{array}$ & $\begin{array}{l}\text { (4) Cardiogenic } \\
\text { shock } \\
(\text { No. }=24)\end{array}$ & $\begin{array}{l}\text { (5) Fibrillation, } \\
\text { asystole, and } \\
\text { shock } \\
(\text { No. }=37)\end{array}$ & $\begin{array}{l}\text { Significance } \\
\text { (1) vs (5) }\end{array}$ \\
\hline $\begin{array}{l}\mathrm{CI}\left(1 / \mathrm{min} \times \mathrm{m}^{2}\right) \\
\text { PAEDP }(\mathrm{mmHg}) \\
\text { SWI }\left(\mathrm{g} \mathrm{m} / \mathrm{m}^{2}\right)\end{array}$ & $\begin{array}{c}3 \cdot 5 \pm 1 \cdot 4 \\
17 \cdot 3 \pm 9 \cdot 8 \\
61 \cdot 0 \pm 11 \cdot 0\end{array}$ & $\begin{array}{c}2 \cdot 4 \pm 1 \cdot 1 \\
20 \cdot 1 \pm 10 \cdot 5 \\
31 \cdot 7 \pm 16 \cdot 3\end{array}$ & $\begin{array}{r}2 \cdot 1 \pm 0 \cdot 3 \\
24 \cdot 0 \pm 6 \cdot 7 \\
34 \cdot 0 \pm 5 \cdot 9\end{array}$ & $\begin{array}{c}2 \cdot 1 \pm 0 \cdot 7 \\
22 \cdot 6 \pm 8 \cdot 7 \\
22 \cdot 9 \pm 11 \cdot 7\end{array}$ & $\begin{array}{c}2 \cdot 2 \pm 0 \cdot 8 \\
22 \cdot 2 \pm 8 \cdot 8 \\
26 \cdot 2 \pm 13 \cdot 1\end{array}$ & $\begin{array}{l}\mathrm{p}<0.005 \\
\mathrm{NS} \\
\mathrm{p}<0.0001\end{array}$ \\
\hline
\end{tabular}

Note: The figures for cardiac index (CI), pulmonary arterial end-diastolic pressure (PAEDP), and stroke work index (SWI) are group means \pm standard deviation. 
irreversible ventricular fibrillation in nine, terminal asystole in four, and cardiac rupture in four. The initial haemodynamic values of cardiac index, pulmonary artery end-diastolic pressure, and stroke work index were similar in patients who died from cardiogenic shock, from fibrillation, and from asystole. In those who died from cardiac rupture, however, cardiac and stroke work index were significantly higher and pulmonary artery end-diastolic pressure was lower compared with the other groups. Classifying the haemodynamic findings in relation to the time elapsed since the onset of infarction (Fig. 4, Table 5) within the first four hours (time group A) we found relatively high values of cardiac and stroke work index in survivors, while these values were already lowered in non-survivors. The average pulmonary artery end-diastolic pressure in survivors was at the upper limit of normal and was slightly raised in non-survivors. From the fifth hour on (time groups B and $\mathrm{C}$ ) cardiac and stroke work indices in survivors and in non-survivors were lower, though not significantly so. Among patients admitted 13 to 24 hours after onset of infarction (time group D) who died in hospital, cardiac and stroke work indices were higher than in patients admitted earlier. The pulmonary artery end-diastolic pressure in this subgroup of non-survivors was also raised. Most of the 18 patients admitted more than 24 hours after onset (time group E) had normal cardiac index, stroke work index, and pulmonary artery end-diastolic pressure; the two non-survivors in this group presented the worst findings of the group.

The mortality rate in the group presenting earliest (group A) was relatively high at $19 \%$. The rate fell to $11 \%$ and $15 \%$ in the groups presenting later (groups B and $C$ ). In patients of group D, who were admitted between 13 and 24 hours after infarction, mortality was again high at $36 \%$. Only two of 18 patients in group $E$ died. In all five time groups the initial pulmonary artery end-diastolic pressure of the

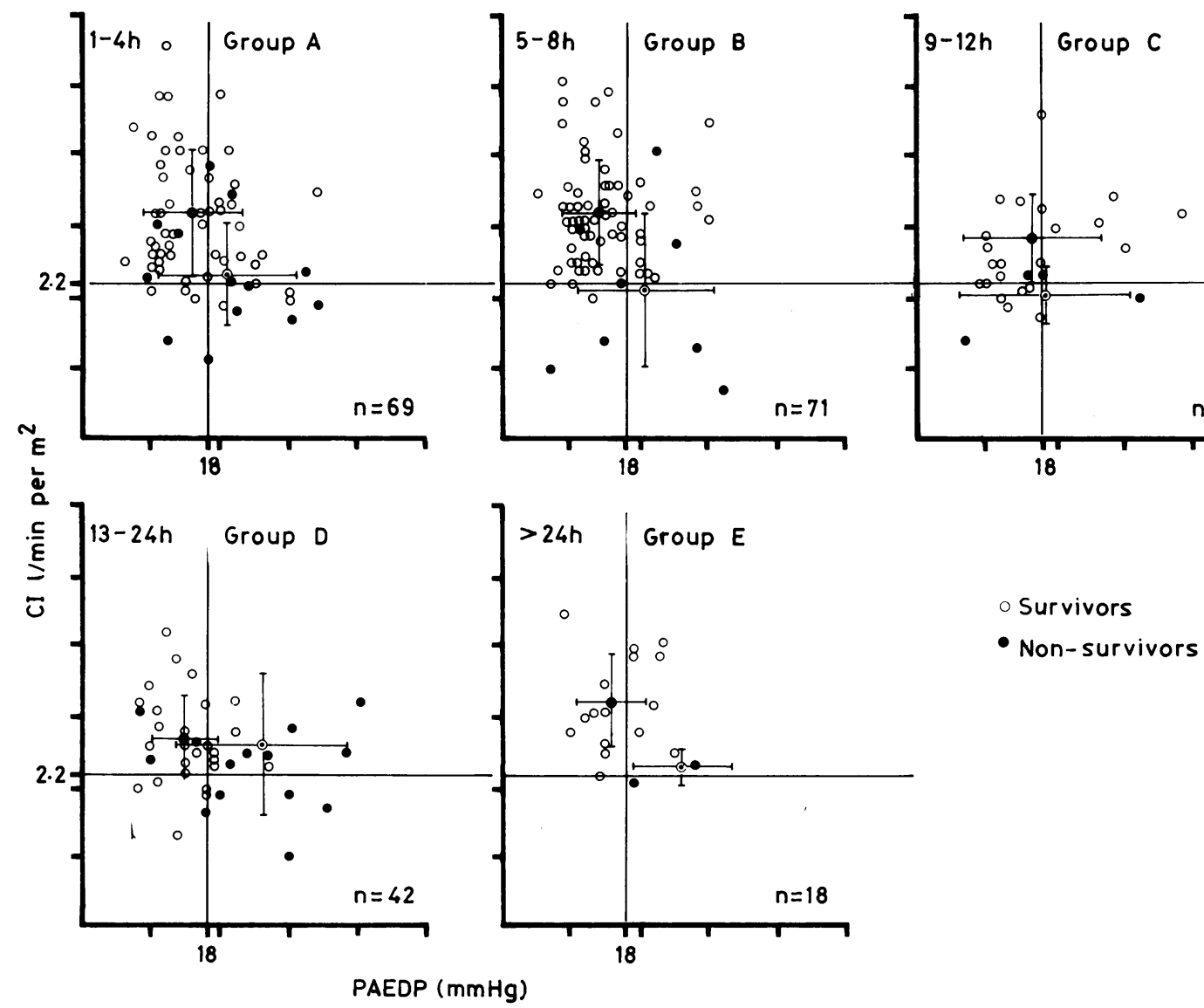

Fig. 4 Initial haemodynamic findings of cardiac index $(C I)$ and pulmonary arterial end-diastolic pressure $(P A E D P)$ in relation to different admission times after onset of infarction. Mean values and standard deviation of survivors and non-survivors. (See Table 5.) 
Table 5 Initial measurements of cardiac index (CI), stroke work index (SWI), and end-diastolic pulmonary artery pressure $(P A E D P)$ in relation to time elapsed after onset of infarction

\begin{tabular}{|c|c|c|c|c|c|c|c|}
\hline \multirow{2}{*}{$\begin{array}{l}\text { Time after } \\
\text { onset of } \\
\text { infarction }\end{array}$} & \multicolumn{3}{|c|}{ Survivors $($ No. $=184)$} & \multicolumn{3}{|c|}{ Non-survivors $($ No. $=42)$} & \multirow{2}{*}{$\begin{array}{l}\text { Mortality } \\
(18 \cdot 6 \%)\end{array}$} \\
\hline & $C I$ & $S W I$ & $P A E D P$ & $C I$ & $S W I$ & $P A E D P$ & \\
\hline $\begin{array}{l}1-4 \text { h } \\
\text { (Group A) }\end{array}$ & $3 \cdot 2 \pm 0 \cdot 9$ & $58 \cdot 8 \pm 28 \cdot 5$ & $16 \cdot 1 \pm 6 \cdot 3$ & $\begin{array}{l}2.3 \pm 0.8 \\
(p<0.002)\end{array}$ & $\begin{array}{l}29.9 \pm 14.9 \\
(p<0.001)\end{array}$ & $\begin{array}{l}20 \cdot 2 \pm 8 \cdot 2 \\
\left(p_{4}^{3} 0 \cdot 056\right)\end{array}$ & $13 / 69(19 \%)$ \\
\hline $\begin{array}{l}5-8 \mathrm{~h} \\
\text { (Group B) }\end{array}$ & $3 \cdot 2 \pm 0 \cdot 8$ & $63 \cdot 2 \pm 24 \cdot 7$ & $15 \cdot 2 \pm 5 \cdot 4$ & $\begin{array}{l}2 \cdot 1 \pm 1 \cdot 2 \\
(p<0.0015)\end{array}$ & $\begin{array}{l}21.9 \pm 13.8 \\
(p<0.0001)\end{array}$ & $\begin{array}{l}19.8 \pm 8.5 \\
(p<0.04)\end{array}$ & $8 / 71(11 \%)$ \\
\hline $\begin{array}{l}9-12 \mathrm{~h} \\
\text { (Group C) }\end{array}$ & $2 \cdot 8 \pm 0 \cdot 7$ & $55 \cdot 1 \pm 24 \cdot 3$ & $16 \cdot 9 \pm 7 \cdot 7$ & $\begin{array}{l}2.0 \pm 0.4 \\
(p<0.04)\end{array}$ & $\begin{array}{l}24.8 \pm 10 \cdot 4 \\
(p<0.03)\end{array}$ & $18 \cdot 3 \pm 10 \cdot 3$ (NS) & $4 / 26(15 \%)$ \\
\hline $\begin{array}{l}\text { 13-24 h } \\
\text { (Group D) }\end{array}$ & $2 \cdot 7 \pm 0 \cdot 6$ & $52 \cdot 0 \pm 17 \cdot 6$ & $15 \cdot 3 \pm 4 \cdot 5$ & $\begin{array}{l}2 \cdot 6 \pm 1 \cdot 0 \\
(\mathrm{NS})\end{array}$ & $\begin{array}{l}35 \cdot 3 \pm 18 \cdot 7 \\
(p<0 \cdot 008)\end{array}$ & $\begin{array}{l}24 \cdot 1 \pm 9 \cdot 5 \\
(p<0 \cdot 0003)\end{array}$ & $15 / 42(36 \%)$ \\
\hline $\begin{array}{l}>24 \mathrm{~h} \\
\text { (Group E) }\end{array}$ & $3 \cdot 2 \pm 0 \cdot 7$ & $60 \cdot 6 \pm 18 \cdot 2$ & $15 \cdot 9 \pm 4 \cdot 4$ & $2 \cdot 3 \pm 0 \cdot 2$ & $37 \cdot 5 \pm 24 \cdot 8$ & $23 \cdot 5 \pm 6 \cdot 4$ & $2 / 18(11 \%)$ \\
\hline
\end{tabular}

$\mathrm{CI}=\mathrm{l} / \mathrm{min} \times \mathrm{m}^{2} ; \mathrm{SWI}=\mathrm{g} \mathrm{m} / \mathrm{m}^{2} ;$ PAEDP $=\mathrm{mmHg}$ ( $\mathrm{p}$ values between survivors and non-survivors).

Note: Results are group means \pm standard deviation.

survivors was almost identical, with a value of $16 \mathrm{mmHg}$. In the group of non-survivors the pulmonary artery end-diastolic pressure was higher and varied in the different time groups. In survivors significant differences in cardiac index were found only between groups $B$ and $C(p<0.05)$ and between groups $\mathrm{D}$ and $\mathrm{E}(\mathrm{p}<0.02)$.

The majority of patients dying later of cardiogenic

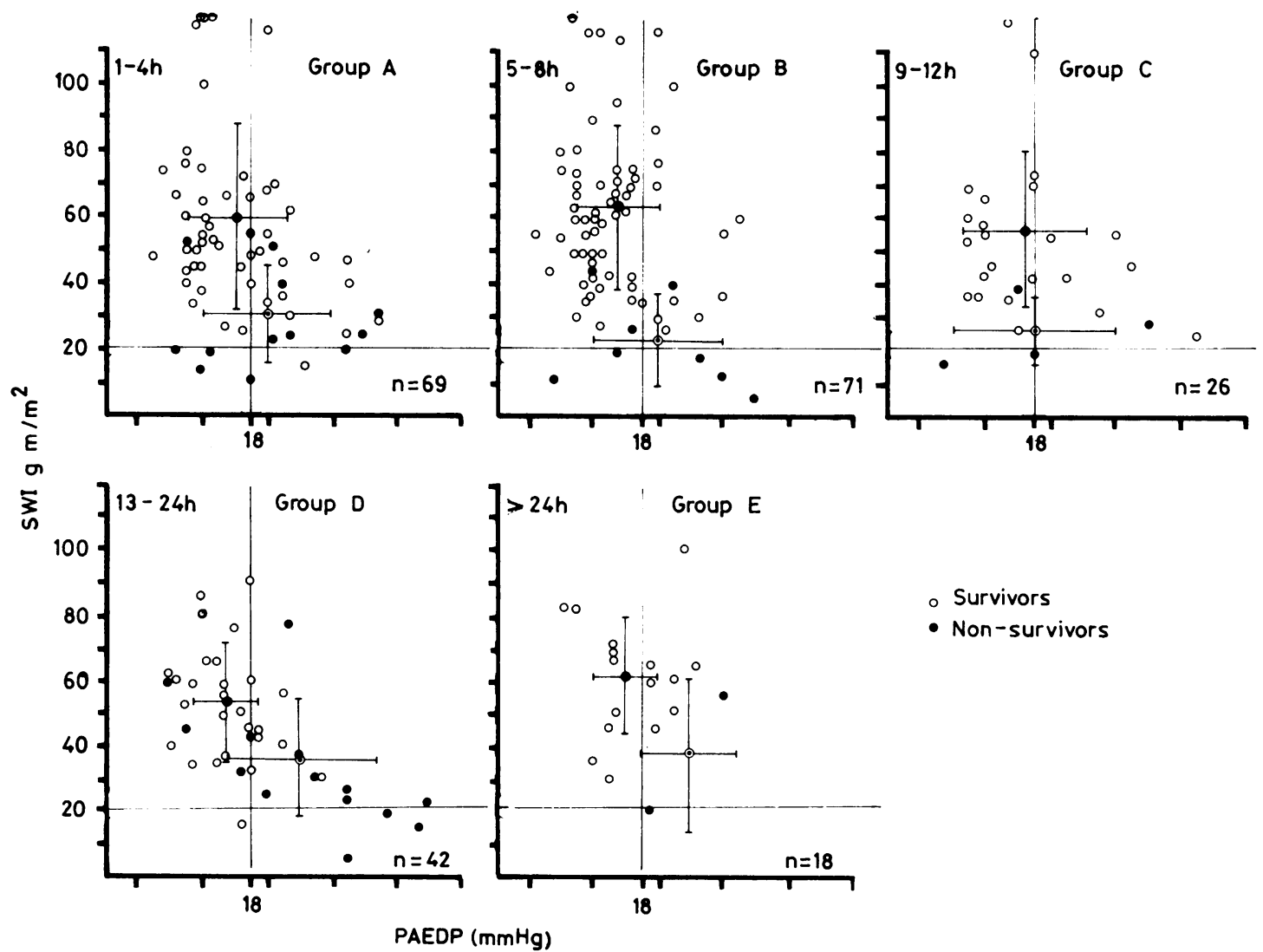

Fig. 5 Initial haemodynamic findings of stroke work index (SWI) and pulmonary arterial end-diastolic pressure (PAEDP) in relation to different admission times after onset of infarction. Mean values and standard deviation of survivors and non-survivors. (See Table 5.) 
Table 6 Cause and day of death after onset of acute myocardial infarction in 42 patients subdivided into groups $A$ to $E$ according to time between onset of infarction and admission to hospital

\begin{tabular}{llrl}
\hline $\begin{array}{l}\text { Time } \\
\text { group }\end{array}$ & $\begin{array}{l}\text { Cause of } \\
\text { death }\end{array}$ & No. & Day of death \\
\hline A & Shock & 10 & $1,1,1,2,2,3,5,5,7,9(3 \cdot 6 \pm 2 \cdot 8)$ \\
$1-4 \mathrm{~h}$ & Fibrillation & 1 & 5 \\
& Asystole & 1 & 2 \\
B & Rupture & 1 & 3 \\
5-8 h & Shock & 5 & $1,1,1,5,7(3 \cdot 0 \pm 2 \cdot 8)$ \\
C Fibrillation & 3 & $1,3,3(2 \cdot 3 \pm 1 \cdot 2)$ \\
$9-12 \mathrm{~h}$ & Shock & 1 & 1 \\
& Fibrillation & 1 & 13 \\
D & Asystole & 2 & 1,1 \\
$13-24$ h & Shock & 8 & $1,1,2,2,2,3,7,29(5 \cdot \pm 9 \cdot 5)$ \\
& Fibrillation & 3 & $2,2,5(3 \cdot 0 \pm 1 \cdot 7)$ \\
& Ruptole & 1 & 13 \\
E & Apoplexy & 2 & 11,20 \\
$>24 \mathrm{~h}$ & Fibrillation & 1 & 43 \\
\hline
\end{tabular}

Note: Means \pm standard deviation for day of death are given in parenthesis.

shock (Table 6) were admitted either within the first eight hours or were delayed between 13 and 24 hours after onset of infarction. Like those dying from intractable ventricular fibrillation and terminal asystole, they died mostly within the first three days. The patients with cardiac rupture died three, four, 11 , and 20 days after infarction; three of them were admitted more than 12 hours after the onset of symptoms.

\section{Discussion}

According to Killip and Kimball, ${ }^{15}$ the clinical staging of cardiac failure in acute myocardial infarction is only reliable in large infarctions with manifest left ventricular failure. In smaller infarctions the clinical signs of pump failure may follow raised pulmonary artery end-diastolic pressure with a delay of up to 12 hours. $^{681016}$ On the other hand, râles may sometimes still be heard despite return to normal of left ventricular filling pressure. In comparison with purely clinical examination pulmonary arterial pressure measurements via balloon catheter ${ }^{1-7}$ allow an immediate, quantitative evaluation of the haemodynamic disturbances and of the effects of treatment. ${ }^{16-20}$ Thus pure clinical, non-invasive techniques are not reliable enough to form the basis for prognosis and evaluation of treatment. Though the haemodynamic findings at any one moment in the individual patient may be useful, they must be regarded critically as isolated values. They ought to form part of a longitudinal analysis and be correlated with the whole clinical picture. They are ideally supplemented by two-dimensional echocardiography
2122 and scintigraphy. ${ }^{23}$ The calculation of infarct size from the creatinine kinase washout curve ${ }^{52}$ in the individual case has not proved sufficiently reliable. ${ }^{25}$

When considering the significance of haemodynamic findings in the early phase of acute myocardial infarction one has to consider the augmentation of stiffness of the infarcted myocardial area by oedema and cellular infiltration which occurs within the first few hours after coronary occlusion. Because of these changes in compliance, left ventricular filling pressure, as reflected by pulmonary artery end-diastolic pressure, rises. Subsequently, the stiffness resolves and pulmonary artery end-diastolic pressure accordingly falls. ${ }^{2} 717182627$ The increased secretion of endogenous catecholamines in this early phase increases simultaneously the contractility of the residual myocardium, causing cardiac and stroke work index to rise. Alterations in left ventricular filling pressure, which occur in most cases of transmural infarction, are not primarily indicative of the prognosis. As long as cardiac and stroke work indices remain normal, pulmonary artery enddiastolic pressure values between 18 and $22 \mathrm{mmHg}$ in this early phase of the infarction are not indications for the immediate use of vasodilators, but should encourage continuous close observation. If cardiac and stroke work index values fall, treatment with positive inotropic agents or even intra-aortic balloon pulsation have to be considered. ${ }^{2} 1618$ Despite this haemodynamic instability in the acute phase, consideration of the initial cardiac index, stroke work index, and pulmonary artery end-diastolic pressure gives some prognostic information. ${ }^{3467928}$ With certain reservations, prognostications for the year after the infarction may also be made from them. ${ }^{1928} 29$ In our series 13 out of 23 patients with pulmonary artery end-diastolic pressure values greater than $28 \mathrm{mmHg}$ and seven out of nine patients with values greater than $32 \mathrm{mmHg}$ died; this corresponds with other reported experience. ${ }^{6} 101216$ With initial cardiac index values below $2 \cdot 2 \mathrm{l} / \mathrm{min}$ per $\mathrm{m}^{2} 20$ out of 44 patients died, and below $1.8 \mathrm{l} / \mathrm{min}$ per $\mathrm{m}^{2}, 12$ out of 15 . None of the eight patients with cardiac index less than $1.4 \mathrm{l} /$ min per $\mathrm{m}^{2}$ survived. When the stroke work index was below $40 \mathrm{~g} \mathrm{~m} / \mathrm{m}^{2} 32$ out of 76 patients died, and 16 out of 18 patients with a stroke work index of less than $20 \mathrm{~g} \mathrm{~m} / \mathrm{m}^{2}$ succumbed; again, similar reports can be cited. ${ }^{478101219}$ Seventy of the 73 patients with values over $60 \mathrm{~g} \mathrm{~m} / \mathrm{m}^{2}$ survived to leave hospital. One patient died from cardiac rupture 20 days after the onset of infarction.

The combined analysis of cardiac index and pulmonary artery end-diastolic pressure is superior to consideration of the single items. ${ }^{2-7} 16-20$ Consideration of pulmonary artery end-diastolic pressure 
alone, without reference to some indication of the degree of pump failure in terms of cardiac and stroke work index, can be misleading. If the cardiac index is below $2.21 / \mathrm{min}$ per $\mathrm{m}^{2}$ and the pulmonary artery end-diastolic pressure at the same time exceeds $18 \mathrm{mmHg}$, mortality is approximately $70 \%$. The analysis of stroke work index shows a certain grey zone between 20 and $40 \mathrm{~g} \mathrm{~m} / \mathrm{m}^{2}$, where the level of pulmonary artery end-diastolic pressure is crucial. In our series with pulmonary artery end-diastolic pressure values below $18 \mathrm{mmHg}$ mortality was $11 \%$; with values above $18 \mathrm{mmHg}$ it rose to $42 \%$. With stroke work index values of less than $20 \mathrm{~g} \mathrm{~m} / \mathrm{m}^{2}$ mortality was $91 \%$ and pulmonary artery end-diastolic pressure values did not provide any additional prognostic information. The seven patients in this group who had pulmonary artery end-diastolic pressure below $18 \mathrm{mmHg}$ had predominant right ventricular infarction and the high mortality in this subgroup $(86 \%)$ perhaps reflects the poor adaptability and limited contractile reserve of the right ventricle.

Patients with a hyperkinetic left ventricle - cardiac index over $3.5 \mathrm{l} / \mathrm{min}$ per $\mathrm{m}^{2}$, stroke work index over $60 \mathrm{~g} \mathrm{~m} / \mathrm{m}^{2}$, and pulmonary artery end-diastolic pressure below $18 \mathrm{mmHg}$ - generally had a good prognosis, but all four patients with cardiac rupture had remarkably high cardiac index and stroke work index findings. Because of raised catecholamine stimulation the contractility of the non-ischaemic myocardium is greatly increased. Thus the infarcted area tends to be expanded in systole and left ventricular wall stress is enhanced. ${ }^{2}$ This increase of wall tension can lead to an expansion of the infarcted area and finally to cardiac rupture. ${ }^{30}$ This mechanism may occur especially in patients like ours who are slow in reaching hospital. In this hyperkinetic state the early administration of beta-blockers may prevent the expansion of the infarction and subsequent myocardial rupture.

There is evidence that the final outcome, including mortality, in acute myocardial infarction depends on the time between onset of infarction and the introduction of relevant treatment after hospital admission. ${ }^{712}$ Our patients admitted within the first four hours often had large infarctions and had perhaps been sent to hospital at an early stage because of severe symptoms. Some were in shock on arrival and responded poorly to treatment. Thus, the group mortality of about $20 \%$ was quite high. Those patients admitted five to 12 hours after onset had a group mortality of $12 \%$; their infarctions were mostly smaller, and the clinical symptoms, the degree of pain, and the signs of cardiac failure less impressive. Sometimes, the admission of patients even with larger infarctions was delayed to the 13th or 14th hour. The detailed questionnaire disclosed that this delay was partly caused by the patients or their relatives and partly by the family physicians. Several of them had already developed pump failure with pulmonary congestion, acidosis, and ventricular rhythm disturbances at the time of admission. The presence of several such high-risk patients within the 13 to 24 hour admission group contributed to its high mortality figure of $36 \%$. Most patients in the small group admitted 24 hours or more after the onset of symptoms had relatively small infarctions with stable haemodynamics and a good prognosis (mortality $11 \%)$.

If haemodynamic measurements in the acute phase of the myocardial infarction are considered without reference to the age of the infarction, findings in patients who have just developed features of shock are mixed up with those in haemodynamically compensated patients with small infarctions in a later phase of the disease. The large American multicentre study ${ }^{10}$ defines an interval of 36 hours after onset of infarction as the criterion of inclusion. This large time interval brings together a broad spectrum of patients at different stages of the acute disease. A pulmonary artery end-diastolic pressure value of $22 \mathrm{mmHg}$ found within the first 12 hours of an infarction may be solely the result of initial left ventricular stiffness and become normal within the next few hours without any treatment and with a good prognosis. If such a value is registered during the 24 th hour it may be a sign of an expanding infarction with incipient pump-failure. It could, however, be a good intermediate finding in a situation improving after initial pump failure, with even higher pulmonary artery end-diastolic pressure values. Like Shell et al. ${ }^{14}$ we found significant prognostic information from the longitudinal comparison of pulmonary artery end-diastolic pressure and cardiac and stroke work indices within the first 48 to 72 hours. ${ }^{12}$ If pulmonary arterv end-diastolic pr

$18 \mathrm{mmHg}$ (mortalı

$2.21 / \mathrm{min}$ per $\mathrm{m}^{2}$

$25 \mathrm{~g} \mathrm{~m} / \mathrm{m}^{2}$ (mortality $5 \%$ ana $4 \%$, respectively), the prognosis of these small, monophasic infarctions was good. If initially abnormal pulmonary artery enddiastolic pressure and cardiac and stroke work indices became normal within the first two days, the outcome was still not too bad (mortality $10 \%, 19 \%$, and $25 \%$ ). If, however, pulmonary artery end-diastolic pressure rose during the first three days (mortality $23 \%$ ) or cardiac and stroke work indices fell, the prognosis was considerably worse (mortality $58 \%$ and $40 \%$ ). Some of these patients were experiencing recurrent ischaemia and perhaps a biphasic pattern of infarction, with or without infarct expansion. With persistently raised pulmonary artery end-diastolic pressure and subnormal cardiac and stroke work indices (mortality 
$47 \%, 65 \%$, and $88 \%$ ) the prognosis was gloomy. In these large infarctions with severe myocardial damage the residual areas of the ventricle were usually unable to maintain adequate cardiac pumping function.

All survivors, irrespective of the timing of their first haemodynamic measurements, had surprisingly similar values of pulmonary artery end-diastolic pressure at around $16 \mathrm{mmHg}$. As a rule, nonsurvivors admitted after the 13th hour had raised pulmonary artery end-diastolic pressures. Cardiac and stroke work indices within the first eight hours were usually somewhat raised and fell later. The capacity of the infarcted ventricle temporarily to pump more blood may be partly an effect of the raised left ventricular filling pressure and partly an effect of increased catecholamine drive. In large infarctions with destruction of much of the left ventricle and in predominantly right ventricular infarctions these compensatory mechanisms are ineffective and pump failure supervenes.

The most unstable phase in the acute myocardial infarction is the first 24 hours. Changes may occur quickly and without warning. If the haemodynamic findings remain stable for 12 to 15 hours during this first day, however, we feel that haemodynamic monitoring can be discontinued. Beyond this time we found the chance of deterioration in previously stable patients to be below $10 \% .^{12}$ Late deterioration is mostly accompanied by the new onset of pain, or by electrocardiographic or creatinine kinase changes. In such circumstances the prognosis is worse and it is our belief that haemodynamic monitoring should be recommended, particularly to enable treatment to be chosen and adjusted optimally.

The patients included in this paper were all treated in the classical way with vasodilators, positive inotropic agents, beta-blockers, and fluid. ${ }^{21618}$ The haemodynamic measurements and follow-up studies will form the basis for comparison of findings in those patients who are now treated in our hospital with selective intracoronary thrombolysis and, in some suitable cases, also with the adjacent application of transluminal balloon dilatation of the underlying coronary artery stenosis. This comparison will disclose whether this aggressive revascularisation within the first eight hours after the onset of the infarction is more capable than conventional treatment of saving myocardium, of preventing an enlargement or a relapse of ischaemia, and of improving prognosis.

\section{References}

1 Swan HJC, Ganz W, Forrester J, Marcus H, Diamond G, Chonette D. Catheterization of the heart in man with use of a flow-directed balloon-tipped catheter. $N \mathrm{Engl} F$ Med 1970; 283: 447-51.

2 Swan HJC, Forrester JS, Diamond G, Chatterjee K, Parmley WW. Hemodynamic spectrum of myocardial infarction and cardiogenic shock: a conceptual model. Circulation 1972; 45: 1097-110.

3 Ratshin RA, Rackley CE, Russell RO Jr. Hemodynamic evaluation of left ventricular function in shock complicating myocardial infarction. Circulation 1972; 45: 127-39.

4 Bleifeld W, Hanrath P, Mathey D, Merx W. Acute myocardial infarction $V$. Left and right ventricular haemodynamics in cardiogenic shock. Br Heart $\mathcal{F}$ 1974; 36: 822-34.

5 Bleifeld W, Hanrath P, Mathey D, Buss H, Effert S. Die Bedeutung der akuten Infarktgröße für die Hämodynamik des linken Ventrikels. Dtsch Med Wochenschr 1976; 101: 1677-84.

6 Forrester JS, Diamond GA, Swan HJC. Correlative classification of clinical and hemodynamic function after acute myocardial infarction. Am f Cardiol 1977; 39: $137-45$.

7 Meyer J. Der frische Herzmuskelinfarkt - Invasive Diagnostik. Verh Dtsch Ges Kreislaufforschg 1979; 45: 76-91.

8 Prakash R, Forrester J, Parmley WW, Swan HJC. Prognostic implications of left ventricular stroke work index (SWI) in acute myocardial infarction (AMI) (abstract). Clin Res 1972; 20: 391.

9 Verdouw PD, Hagemeijer F, van Dorp WG, van der Vorm A, Hugenholtz PG. Short-term survival after acute myocardial infarction predicted by hemodynamic parameters. Circulation 1975; 52: 413-9.

10 Weber KT, Janicki JS, Russell RO, Rackley CE. Identification of high risk subsets of acute myocardial infarction. Am f Cardiol 1978; 41: 197-203.

11 Rotmensch HH, Terdiman R, Cheffer M, Elkayam U, Laniado S. Dynamic prognostic profile for acute myocardial infarction. Chest 1979; 76: 663-7.

12 Meyer J, Erbel R, Rupprecht J, Merx W, Effert S. Frühe prognostische Aussagen aus dem Verlauf der hämodynamischen Untersuchungen beim akuten Myokardinfarkt. Dtsch Med Wochenschr 1981; 106: 526.

13 Chatterjee K, Swan HJC. Hemodynamic profile of acute myocardial infarction. In: Corday E, Swan HJC, eds. Myocardial infarction. Baltimore: Williams \& Wilkins, 1973: 51-61.

14 Shell WE, Stankus K, Mickle D, Swan HJC. Early assessment and alteration of left ventricular filling pressure following myocardial infarction (abstract). $A m \mathcal{F}$ Cardiol 1979; 43: 394.

15 Killip T, Kimball JT. Treatment of myocardial infarction in a coronary care unit. A two year experience with 250 patients. Am $\mathcal{F}$ Cardiol 1969; 20: 457-64.

16 Forrester JS, Diamond G, Chatterjee K, Swan HJ. Medical therapy of acute myocardial infarction by application of hemodynamic subsets. $N$ Engl f Med 1976; 295: 1356-62 \& 1404-13.

17 Franciosa JA, Guiha NH, Limas CJ, Rodriguera E, Cohn JN. Improved left ventricular function during nitroprusside infusion in acute myocardial infarction. Lancet 1972; i: 650-4. 
18 Bleifeld W, Hanrath P. Die hämodynamische Basis der Therapie des akuten Myokardinfarktes Dtsch Med Wochenschr 1975; 100: 1345-50.

19 Chatterjee K, Swan HJC, Kaushik VS, Jobin G, Magnusson P, Forrester JS. Effects of vasodilator therapy for severe pump failure in acute myocardial infarction on short-term and late prognosis. Circulation 1976; 53: 797-802.

20 Effert S, Merx W, Meyer J. Therapeutische Möglichkeiten in der Intensivstation. Verh Dtsch Ges Kreislaufforschg 1978; 44: 119-29.

21 Eaton LW, Weiss JL, Bulkley BH, Garrison JB, Weisfeldt ML. Regional cardiac dilatation after acute myocardial infarction Recognition by two-dimensional echocardiography. $N$ Engl $\mathcal{f}$ Med 1979; 300: 57-62.

22 Erbel R, Schweizer P, Meyer J, Grenner H, Krebs W, Effert S. Bestimmung der Volumina und der Ejektionsfraktion des linken Ventrikels aus dem zweidimensionalen Echokardiogramm bei Patienten mit koronarer Herzerkrankung. Z Kardiol 1980; 69: 52-61.

23 Shah PK, Pichler M, Berman DS, Singh BN, Swan HJC. Left ventricular ejection fraction determined by radionuclide ventriculography in early stages of first transmural myocardial infarction. Am $\mathcal{F}$ Cardiol 1980: 45: 542-6.

24 Sobel BE, Bresnahan GF, Shell WE, Yoder RD. Estimation of infarct size in man and its relation to prognosis. Circulation 1972; 46: 640-8.
25 Merx W. Herzmuskelinfarkt - nicht invasive Diagnostik. Verh Dtsch Ges Kreislaufforschg 1979; 45: 61-75.

26 Crexells C, Chatterjee K, Forrester JS, Dikshit K, Swan HJC. Optimal level of filling pressure in the left side of the heart in acute myocardial infarction. $N$ Engl $\mathcal{F}$ Med 1973; 289: 1263-6.

27 Forrester JS, Diamond G, Parmley WW, Swan HJC. Early increase in left ventricular compliance after myocardial infarction. 7 Clin Invest 1972; 51: 598-603.

28 Kupper W, Bleifeld W, Hanrath P, Mathey D, Effert S. Left ventricular hemodynamics and function in acute myocardial infarction: studies during the acute phase, convalescence and late recovery. Am $\mathcal{F}$ Cardiol 1977; 40: 900-5.

29 Rogers WJ, Smith LR, Oberman A, Mantle JA, Russell RO Jr, Rackley CE. Invasive measurements relating to long-term survival post-myocardial infarction (abstract). Circulation 1979; 60, suppl II: 232.

30 Schuster EH, Bulkley BH. Expansion of transmural myocardial infarction: a pathophysiologic factor in cardiac rupture. Circulation 1979; 60: 1532-8.

Requests for reprints to Professor Jürgen Meyer, Department of Internal Medicine I, RheinischWestfälische Technische Hochschule, Aachen, Goethestrasse 27/29, D 5100 Aachen, West Germany. 